(6) OPEN ACCESS

${ }^{1}$ Sports Science and Sports Medicine Unit, Tennis Australia, Melbourne, Victoria, Australia

${ }^{2}$ Sport and Exercise Discipline Group, UTS: Health, University of Technology Sydney, Sydney, New South Wales, Australia

\section{Correspondence to}

Dr Machar Reid, Sports Science and Sports Medicine Unit, Tennis Australia, PO Box 6060 Richmond, Melbourne 3121, VIC, Australia;

mreid@tennis.com.au

Accepted 12 January 2014
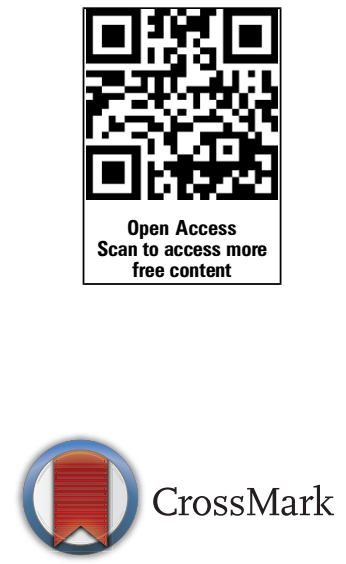

To cite: Reid M, Duffield R. Br J Sports Med 2014:48: i7-i11.

\title{
The development of fatigue during match-play tennis
}

\author{
Machar Reid, ${ }^{1}$ Rob Duffield ${ }^{2}$
}

\begin{abstract}
Data describing the activity profile and physiological

characteristics of tennis match-play are extensive.

However, these data have generally provided descriptive accounts of the one-off match-play of amateur or lowly ranked professional players lasting $<3 \mathrm{~h}$. Accordingly, these research efforts have likely failed to fully capture the demands of Grand Slam tennis match-play, particularly in the men's game where matches can last $>5 \mathrm{~h}$. Furthermore, there is a distinct lack of evidencebased insight regarding the manifestation of fatigue within and between tennis matches, notwithstanding that skeletal muscle function has been reported to reduce following prolonged match-play. Moreover, it is evident that match-play evokes pronounced and prolonged physiological, neuromuscular and psychological perturbations that may be exacerbated with consecutive days of match-play. Separate to these internal load responses, a collection of non-uniform movement and technical performance changes are reported, though rarely from match-play data. Consequently, direct or causal links between altered physiological or muscle contractile function and subsequent match-play outcomes are lacking. Indeed, emerging evidence seems to infer that players adjust their game strategy, and the resultant execution of stroke play, to accommodate any such deterioration in physiological function. The purpose of this review was to discuss the available literature in terms of the physiological, mechanical and psychological responses that occur during prolonged match-play in the context of their likely effect on match-play performance.
\end{abstract}

\section{INTRODUCTION}

Classical descriptions of tennis present an activity characterised by prolonged durations $(2-4 \mathrm{~h})$ of repeated, high-intensity bouts interspersed with standardised rest periods. ${ }^{1}$ Indeed, such descriptions form the basis on which the sport is then pronounced as physically and physiologically demanding. ${ }^{2}{ }^{3}$ However, tennis match-play can potentially last in excess of $5 \mathrm{~h},{ }^{4}$ and given the lack of literature quantifying such extended matches, it is likely that the physiological load is much greater than is classically described. ${ }^{1-4}$ In other words, with additional context, it is possible to garner a more granular appreciation of the physical and physiological loads that players withstand in the upper echelons of the game. Accordingly, previous research descriptions of internal and external load may fail to appropriately portray the demands of professional tournament match-play.

With this in mind, it is instructive to use the journeys of Novak Djokovic (ND) and Rafael Nadal (RN) through the Australian Open in 2012 as cases in point. That is, they each played over $12 \mathrm{~h}$ of tennis across 13 days before competing in a final that lasted $5 \mathrm{~h} 53 \mathrm{~min}$. This volume of work represents acute and cumulative workloads that far exceed any empirical investigation describing tennis loads or fatigue. The final saw the two players compete in 369 points, and, according to Tennis Australia's (2012) unpublished Hawkeye data, traverse in-point distances greater than $6 \mathrm{~km}$ (ND: $6625 \mathrm{~m}$ and $\mathrm{RN}: 6219 \mathrm{~m}$ ). The players covered approximately 10\% more ground when losing points than when winning, and reached maximum speeds in excess of $20 \mathrm{~km} / \mathrm{h}$. Throughout the match, in excess of $40 \%$ of points ( 203/461) involved more than eight shots and the players hit over 1100 groundstrokes at average velocities of $>95 \mathrm{~km} / \mathrm{h}$ (RN: $97 \mathrm{~km} / \mathrm{h}$ and ND: $107 \mathrm{~km} / \mathrm{h}$ ). While the advent of technologies like Hawkeye will allow for these data to inform the interaction between performance and fatigue and, therefore, player preparation in the future, they remain largely unreported, leaving practitioners to lean on the available literature of singular, simulated match-play efforts of comparatively short $(<3 \mathrm{~h})$ durations. Indeed, while the Djokovic-Nadal example may seem extreme, and only related to Grand Slam events, top tier professionals must be prepared for and expected to tolerate such loads. To this end, this depicts a demanding scenario of a prolonged $>5 \mathrm{~h}$ 'marathon' match, preceded by six matches lasting $2-4 \mathrm{~h}$ and separated by $<48 \mathrm{~h}$ recovery. Such a scenario highlights the volume and inherent variability in the loads of professional tennis match-play, whereby acute (within) and residual (between) match fatigue are presumably induced. That the quantification of the effects of fatigue on matchplay remains equivocal, and is confounded by the effect of court surface ${ }^{5}$ and the combatants' game styles, ${ }^{4}$ further complicates an already difficult narrative. For example, hypothetically game styles requiring regular movement to the net, that is, serve-volley players, may induce greater physiological loads owing to their very dynamic, highintensity movement. However, it could also be argued that lower physiological loads may result from the comparatively shorter point durations typical of the serve-volley game style. Intuitively the former scenario appears more likely, and game styles punctuated with repeated changes of directionsupported by regular high-intensity eccentric muscle contractions of the lower limb-may manifest more obviously with reduced or suboptimal movement patterns (as a result of 'fatigue'). Conversely, following this logic, it may be difficult to distinguish changes in movement patterns due to 'fatigue' in typical baseline players, whereby stroke outcomes may be a more verifiable indicator as to a fatigue-induced reduction in performance. Either way such information is speculative given its 
absence in the literature, and consequently the description of fatigue in the tennis research literature may inadequately represent the demands facing elite players.

More generically, fatigue is considered the exercise-induced reduction in the force generating capacity of muscle, ${ }^{6}$ wherein its manifestations in tennis are presumed to vary. The aforementioned high-intensity, intermittent, skill-based nature of the sport partly challenges definitive classifications of fatigue in tennis. That is, where definitions of fatigue in some field sports reference a reduction of peak speed or power output between multiple efforts, ${ }^{78}$ the activity profile of tennis does not easily conform to such definitions. Empirical evidence highlights acute reductions in postmatch lower-body force production and sprint times following $<3 \mathrm{~h}$ simulated match-play, ${ }^{9}{ }^{10}$ though withinmatch changes and the relationship to performance are difficult to decipher. Indeed, whether fatigue in tennis manifests in changes to locomotion, technical proficiency or cognitive performance is unclear. Correspondingly, the extent to which these changes might inform match outcomes remains speculative. Furthermore, the physiological state of athletes at the culmination of a match (or tournament) and residual effects for ensuing competition also remain difficult to define in the context of fatigue. Consequently, the focus of this review is to contextualise fatigue in relation to tennis match-play.

\section{Physiological profile}

The activity profile of tennis has been directly investigated, generally through a mix of game notation and quantitative techniques, and summarised often. ${ }^{4} 11 \quad 12$ In-point times approximating $20-30 \%$ of total match time, ${ }^{13}$ with exercise-to-rest ratios of $\approx 1: 2,{ }^{4}{ }^{11-16}$ and mean point lengths bordering $8 \mathrm{~s}$ are often reported. ${ }^{9}{ }^{17}$ Modest mean physiological responses punctuate typical singles tennis match-play; with exercise intensities approximating $60-80 \%$ of maximal heart rate, $60-70 \%$ maximal oxygen consumption and blood lactate concentrations rarely observed to exceed $5 \mathrm{mmol} / \mathrm{L}$-albeit in flux over prolonged durations. ${ }^{10} \quad 11 \quad 17 \quad 18$ Cardiac and ventiliatory responses to match-play are reported as relatively stable, ${ }^{11}$ yet susceptible to variation in accordance with rally intensity, ${ }^{14}$ individual game styles ${ }^{19}$ and game situation. ${ }^{20}$ Thermoregulatory demands are genrally low, though may be elevated in hot playing conditions $\left(>39.0^{\circ} \mathrm{C}\right)$, yet core temperatures are rarely reported above critical thresholds, ${ }^{21}$ and excluding medical emergencies, are not reported to relate to performance outcomes. Although hormonal responses including elevated testosterone and reduced cortisol concentrations are common in tennis literature, ${ }^{22} 23$ and are certainly indicative of the interaction between anabolic and catabolic stresses, do not appear related to performance outcomes. $^{22} 24$ That said, some evidence suggests divergent cortisol responses in winners and losers ${ }^{23}$; though whether this is a product or antecedent of match success is debatable. Exercise-induced muscle damage resulting from match-play is likely of more immediate and tangible concern to practitioners. Although only reported from matches of less than $3 \mathrm{~h}$, previous research suggests significant postmatch elevations in markers of cell damage and stress (ie, creatine kinase). ${ }^{5} 22$ Again, however, any relationship to reduction in movement ability or stroke dynamics remains elusive. Furthermore, these characterisations of the physiological and metabolic responses to match-play have been invariably limited to lower ranked professional players ${ }^{5} 11$ and/or in practice match-play lasting $\leq 120 \mathrm{~min}^{22}$

Although the aforementioned physiological responses represent important descriptors of physiological load and not necessarily putatative mechanisms of fatigue; hypohydration and reduced glycogen availability may have some bearing on tennis performance. $^{325-27}$ Hornery et $a l^{5}$ reported reductions in serve performance in a hypohydrated state, even though core temperatures remained below $39^{\circ} \mathrm{C}$. Moreover, carbohydrate ingestion, in addition to the replinishment of fluid, is reported to be important during simulated tennis match-play. ${ }^{28}$ Given the prolonged durations of match-play, muscle glycogen availability or supply via exogenous glucose intake is likely to be a determining factor in the prevention of peripheral and central fatigue. ${ }^{5} 28$ Accordingly, and as is often reported, ${ }^{3}{ }^{25-27}$ optimal nutritional and hydration strategies are presumably critical, particularly in preparation and throughout the 'marathon' competitive matchplay described above. However, of note is the seemingly exacerbated increase in physiological load when match-play is performed on consecutive days-even when respective day match-play is $\sim 2 \mathrm{~h}^{22}$ Specifically, increased markers of muscle damage and stress hormones are evident on days 2 and 3 of match-play, highlighting the potential for increased internal physiological strain at the start of play on ensuing days.

So far, besides dehydration and hypoglycaemia, the physiological load invoked by tennis match-play represents the internal load responses to the match demands rather than an explanation of performance reduction. Such physiological generalisations likely oversimplify game demands, whereby a host of extraneous factors also contribute to the game's bandwidth of physiological responses. ${ }^{11}$ In general, the aerobic demands of match-play have been purported to increase in the female game and with slower surfaces, type 3 balls (ie, larger balls), longer match durations and more baseline play, while match-play by men, on fast surfaces, with type I balls and when characterised by shorter match durations and/or more serve and volley play increase the anaerobic demands. ${ }^{29}{ }^{30}$ Consequently, the physiological response to tennis match-play is expected to be in proportion to the physical demands, match engagement and environmental context. While there is no doubt that the physiological demands of tennis can be profound, as yet, conclusive evidence for a physiological/ metabolic rationale for fatigue in tennis is lacking. Simply, while these physiological responses represent internal loads; they do not represent fatigue per se.

\section{Movement characteristics}

Movement in tennis remains a difficult concept to measure or to classify according to locomotive movement classes typical of time-motion analysis in other field sports. ${ }^{31}$ A collection of descriptive research outlines match-play to require players to cover $3 \mathrm{~m}$ per shot for a total of $8-12 \mathrm{~m}$ per point over $6-8 \mathrm{~s}$ duration $^{17} 32$ resulting in $600-800 \mathrm{~m}$ per set. The work of Ferrauti et $a l^{33}$ further scrutinised these gross movement demands, classifying $\sim 80 \%$ of all strokes to be played within $2.5 \mathrm{~m}$ of the player's ready position and approximately $10 \%$ of strokes requiring players to traverse $2.5-4.5 \mathrm{~m}$. Significantly, in these above examples, the extent to which movement or 'footwork' patterns change over the course of a match-and whether such changes are a result of fatigue, or an adjustment to altered technical demands (or both) is ambiguous. While difficult, such differentiation is important as movement path changes, that is, movement patterns to the ball as part of the technical approach are known to increase oxygen cost. ${ }^{34}$ For example, an analysis of encounters between Roger Federer and RN on grass and clay courts ${ }^{35}$ revealed more path changes of $45^{\circ}-135^{\circ}$ to the left on grass courts, while clay court play was characterised by a larger proportion of braking movements and accelerations from stationary states. Regardless, it could be argued that locomotor classifications largely become redundant given the regular and 
rapid changes in movement enforced due to court surface and game styles (ie, figure 1). Whether match-play movement patterns change is unknown, and moreover, whether they change in response to accumulating physiological loads and skeletal muscle damage, or whether they represent altered tactical play, remains speculative.

The use of Hawkeye as an officiating and now broadcast tool in elite tennis has provided the movement data that informs the Djokovic-Nadal example above. However, as previously inferred, the exclusivity of these data has thus far precluded research from applying this technology to probe within or between match change in movement demands, as could be representative of a potential fatiguing state. Of lower resolution, though greater accessibility, figure 2A,B shows unpublished research by our group using accelerometry data housed in Global Positioning Satellite (GPS) devices during match-play. ${ }^{36}$ These data suggest changes in the relative contribution of the different movement vectors (in the three planes of movement) to occur within $4 \mathrm{~h}$ of match-play and also between consecutive days of $4 \mathrm{~h}$ match-play. Clearly over prolonged $4 \mathrm{~h}$ match-play and then again after 3-4 consecutive days of match-play, there is a reduction in overall movement patterns $(\sim 5 \%$ within respective days and $\sim 15 \%$ from day $1-4)$. Whether this profile represents fatigue, or alternatively, a deliberate change in game style remains the subject of further investigation. This is particularly the case given. figure $2 \mathrm{~B}$ highlights a reduction in effective time in play over consecutive days, suggesting a change in engagement in match-play-either by way of motivation or as a result of soreness and residual fatigue from the play of previous days. From a practical perspective, the mechanisms are of less relevance, though classical notions of fatigue would suggest an

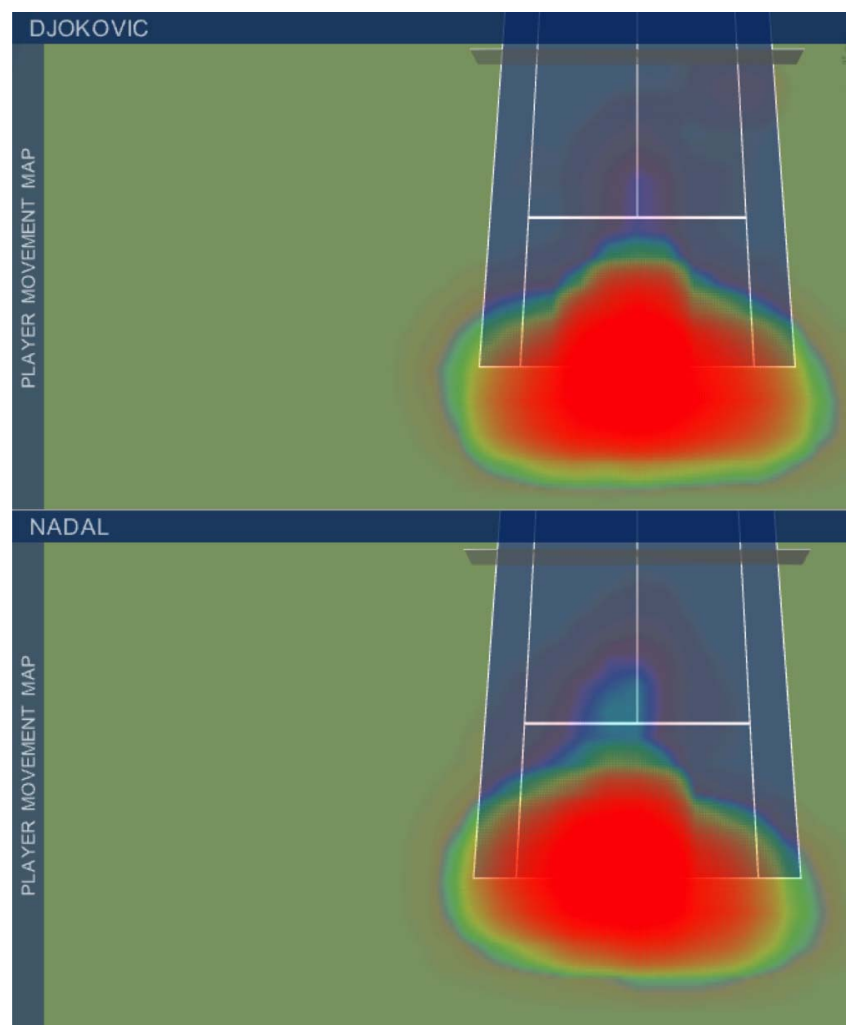

Figure 1 Hawkeye data of the Djokovic-Nadal Australian Open 2012 final. The heat map illustrates the difficulty in determining appropriately sensitive measures of fatigue based on movement patterns in match-play tennis. inability to perform at required exercise intensities precedes a decline in movement and possibly stroke play outcomes. Yet, other theories may hold that tactics are altered to, in turn, preserve the physiological integrity and capacity for movement patterns. Regardless of the theoretical mechanism, currently the research literature remains equivocal about the presence of change in movement characteristics and whether these cause or are in response to developing physiologically induced fatigue.

Despite the above examples, of note is also the measurement challenge posed by the dynamics of tennis movement and evidenced through previous findings, ${ }^{37}$ which illustrated the inefficacy of GPS. Nevertheless, Ojala and Hakkinen ${ }^{22}$ report increased work-to-rest ratios within $40 \mathrm{~min}$ increments of a $2 \mathrm{~h}$ match, which remains similar over three consecutive days. Despite the differences in measures used, the above research infers changes in match-play engagement within and between days of match-play. However, it is clear that there is a gap in the existing evidence base when it comes to understanding whether reductions in movement and hitting patterns occur during prolonged tournament-based match-play, akin to research suggesting reductions in movement speeds and distances observed in the second half of football matches. ${ }^{38}$ Given the stochastic movement patterns of tennis, it is likely these patterns are the product of the tactical and technical nuance of match-play (ie, opponent, court surface and tactical style) and dictate physiological responses.

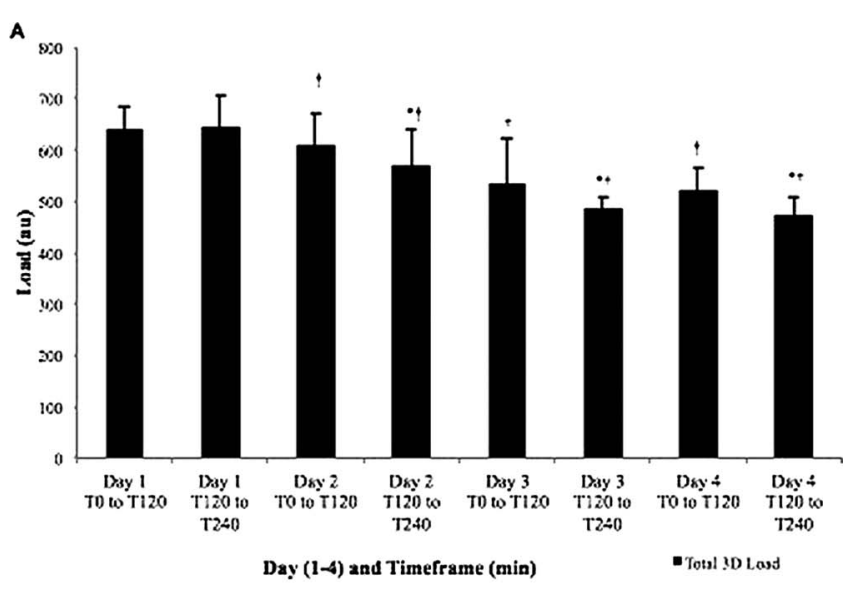

T, - Imsrediately prior to match-playintas - Immediz:ely post match-play. $+-\geq 75 \%$ likely regative change in comparison to day 1 at the sume time point - $-275 \%$ lixely regative elange between $T_{6}$ and $T_{\text {ine }}$ on the same diy

B

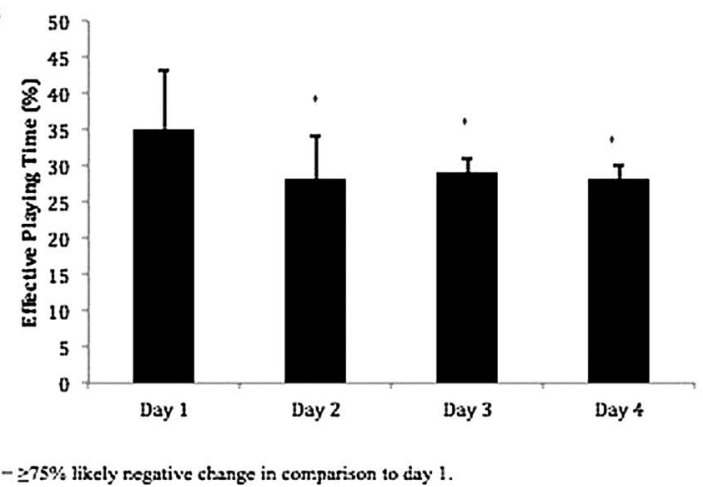

Figure 2 Unpublished (A) total three-dimensional accelerometer load and $(B)$ effective playing time data from prolonged $(4 \mathrm{~h})$ match-play on repeated days. Trends for reduced movement within and between respective days are evident, though whether it is causative or dictated by tactical changes remains speculative. Republished with permission of Gescheit et al. ${ }^{36}$ 


\section{Changes in mechanical, contractile and cognitive} characteristics

Current discussions have shown a research bias towards the notion of fatigue being of physiological bases and manifesting in altered locomotor movement patterns. As evidenced above, few studies have reported the deleterious effects of fatigue on stroke performance, or, more simply the changes in stroke performance/outcomes following highly repetitious stroke and movement production. For example, researchers have variously observed decreases in serve and groundstroke velocity either as training and matches progress $3-5182539$ or subsequent to their completion. Interestingly, previous research ${ }^{1025}$ found that the reductions in serve and groundstroke velocity were not necessarily accompanied by concomitant decreases in accuracy. More specifically, selective decreases in groundstroke $(\approx 70 \%)$ and serve $(\approx 30 \%)$ accuracy were evident following the Loughborough Intermittent Tennis Test, ${ }^{18}$ which superficially agrees with the reductions observed in stroke accuracy within other simulated or training environments. ${ }^{40} 41$ Despite this agreement, on deeper investigation, few studies show similarities in the reported type and extent of stroke accuracy reductions. Even then, not all studies support the relationship between increased physical stress from high-intensity movements and reductions in stroke performance. ${ }^{10} 42$ However, a limitation of the inferences of the deleterious effects of fatigue on tennis stroke play is that few data probe changes in stroke play in competitive match-play. Through using surrogate approaches to assist the understanding of this relationship, it is noted that 'expert' players show greater fatigue resistance and less decrement in stroke accuracy than less well-trained counterparts ${ }^{43}$ during stroke-play in scenarios 'representative' of match-play. Further, when players undergo 6 weeks of fatigue-resistance training (medicine ball and overweight racket swings) in excess of regular hitting practice, an ability to increase stroke velocity, though somewhat at the expense of accuracy, is evident during specific cross-court hitting tasks. ${ }^{44}$ Hence, while the causation of stroke-play-related reductions in performance are unknown, it would appear as though stroke velocity and accuracy can be altered under match-play conditions with particular training interventions.

The application of this relatively narrow empirical lens to the interaction of fatigue and the dynamics of stroke production has led to a number of discrete investigations of the links between the outcome of stroke production (ie, racket or ball velocity) and selected physical capacities. Indeed, these investigative efforts are vast, performed among tennis playing cohorts of variable age, gender and playing level, and often presenting inconsistent results. ${ }^{45-47}$ By way of example, the service and forehand velocity (down-the-line) of intermediate junior players has been shown to positively and linearly relate to the peak torque produced in overhead, diagonal throwing motions and in shoulder joint internal rotation, respectively. ${ }^{45}$ Positive associations between the trunk rotation and flexion strength of elite junior players and medicine ball throwing distance have also been revealed. ${ }^{46} 47$ In female collegiate players, serve, forehand and backhand velocity moderately correlated with military press performance but not other strength measures, ${ }^{48}$ while isometric and isokinetic knee extension and flexion strength as well as isometric internal and external rotation dominant arm strength shared moderate-to-high positive assoications to various shots. Paradoxically, the work of Pugh et $a l^{49}$ has unearthed limited evidence of relationships between leg, shoulder and wrist strength measures and serving speeds. Such a collection of evidence highlights a generally ambiguous association between respective stroke dynamics and joint strength measures, though further associations between fatigue in these various musculoskeletal movement patterns and reduced stroke perfomance are required.

Despite this ambiguity, it is patently clear that the skeletal muscle contractile function reduces following prolonged tennis match-play. ${ }^{50}$ Several studies report the blunted ability to maximally produce force or maximise muscle recruitment following prolonged match-play. ${ }^{51}$ A collection of evidence notes the reductions in running speed, ${ }^{10}$ maximal voluntary strength $(\sim 10-13 \%$ in quadriceps) and leg stiffness during matchplay. $^{22} 5051$ These examples explicitly highlight that there is a reduction in neuromuscular function, particularly of the lower body, during match-play greater than $2 \mathrm{~h}$. Further, maximal voluntary contraction is reported to be reduced over consecutive days of match-play. ${ }^{22}$ Interestingly, there is contrary evidence that reports no difference in neuromuscular performance (countermovement jump height) at various stages throughout $90 \mathrm{~min}$ of similarly intensive on-court work. ${ }^{52}$ However, the discrepancies reported here are likely due to the duration and intensity of the type of on-court work performed. Regardless, such reduction in isolated joint strength or lower-body power suggests an inability to maximise skeletal muscle force production following match-play, ${ }^{6}$ yet whether this reduction in contractile function precedes the reduction in movement activity profiles or relates to the accumulating physiological load remains unknown. While it would be intuitive and convenient to associate reduced skeletal muscle function with altered stroke play characteristics, such associations are absent or at best equivocal in the research literature.

Yet to be discussed, but of high importance for elite players, is their perception of fatigue, either during prolonged match-play or over consecutive days. Simulated and actual match-play result in elevated ratings of perceived exertion, muscle and joint soreness and suppressed mood states. ${ }^{51}$ These negative states of perceived wellness and soreness are then exacerbated by consecutive on-court efforts. ${ }^{22}$ Recent evidence highlights that the cognitive load, as inferred from perceived mental exertion, is associated with perceived physical exertion of on-court tennis training, though data from match-play is not available. ${ }^{53}$ Again, the limitation of this research is that while possible surrogate factors of fatigue are proposed, if not quantified, in simulated tennis matchplay or training - few studies report these variables in competitive scenarios, and as yet no research shows causative relationships with tangible match outcomes. Accordingly, it is evident that players perceive fatigue at the end of match-play via increased rating of perceived exertion $(\mathrm{RPE})^{51}$ - though whether movement demands or stroke outcomes are altered in accordance with this perceived fatigue is speculative. Further, whether physiological bases of fatigue are present, or whether reductions in the motivation to perform are altered, is a time-honoured question. ${ }^{50}$ Also it should be recognised that the reduction in motivation to perform may be viewed as part of the fatigue process, irrespective of the capacity of the skeletal muscle to contract. ${ }^{79} 25$ It is also certainly plausible that an increased perception of exertion (mental or physical) may alter technical and tactical engagement, and thus affect movement patterns and physiological responses; however, this has not been established in prolonged match-play scenarios. In a patchwork approach, previous research does highlight increased RPE and mental exertion to prolonged and intense match-play, ${ }^{51}$ increased error rates throughout longer or more taxing drills and simulated play ${ }^{18}$ and a slowing of movement and hitting demands throughout repeated high-intensity on-court drills. ${ }^{42}$ Collectively, a case could be made for exertion 
and motivation to be affected by the physical state, and thus alterations in stroke play and/or movement patterns. However, these studies occur in fabricated environments without true opposition dictating match-play characteristics. Accordingly, the motivation to perform within a research setting is distinct from the motivation to perform within competitive scenarios and the inference made about match performances from noncompetitive environments is appropriately tenuous. As such, further research is required to tease out factors of fatigue, as distinct from motivation, and their association with performance outcomes in match-play tennis.

\section{Practical applications}

- Tennis match-play can potentially last in excess of $5 \mathrm{~h}$, meaning that it is likely the physiological load is much greater than is classically described.

- The effect of fatigue on movement and stroke outcomes in tennis is unclear, leaving coaches to speculate as to the most appropriate preparatory methods for their players.

- Emerging evidence points to repeated days of match-play affecting the physical condition and tactical intent of players.

\section{Future research}

- How do age, gender and game style interact to affect the dynamics of tennis movement?

- Can we meaningfully distinguish between lower body and upper body workload in tennis?

- How are the dynamics of tennis movement and stroke production affected over prolonged and repeated matches?

- Do tennis players 'pace' are decisions made and shots selected to preserve physical condition?

- How can workload and fatigue information be interpreted by coaches to improve the physical integrity of players?

\section{CONCLUSION}

Research describing the activity profile, and more particularly the physiological characteristics of tennis match-play, is extensive. These investigative efforts have typically and preferentially focused on the quantification of the physiological characteristics of one-off match-play performed by amateur or low-ranked professional players lasting $<3 \mathrm{~h}$, thereby failing to reflect the demands of competitive match-play in the upper echelons of the sport. The data also provide limited empirical insights into the manifestation of fatigue in tennis, notwithstanding that skeletal muscle function is understood to reduce following prolonged match-play. Indeed, emerging evidence would appear to point to players altering their tactical and, therefore, technical strategies to accommodate any such deterioration in physiological function. Based on the available literature, future research wishing to investigate fatigue in match-play tennis should consider methodological approaches that examine physiological and neuromuscular alterations within and between matches alongside their effect on technical, decision-making and movement skills.
Acknowledgements The authors would like to thank Danielle Gescheit and Alistair Murphy for their assistance throughout the manuscript preparation.

Contributors Both MR and RD contributed equally to the design, planning, reviewing and writing of this article.

\section{Competing interests None.}

Provenance and peer review Commissioned; externally peer reviewed.

Open Access This is an Open Access article distributed in accordance with the Creative Commons Attribution Non Commercial (CC BY-NC 3.0) license, which permits others to distribute, remix, adapt, build upon this work non-commercially, and license their derivative works on different terms, provided the original work is properly cited and the use is non-commercial. See: http://creativecommons.org/ licenses/by-nc/3.0/

\section{REFERENCES}

1 Mendez-Villanueva A, Fernandez-Fernandez F, Bishop D, et al. Activity patterns, blood lactate concentrations and rating of perceived exertion during a professional singles tennis tournament. Br J Sports Med 2007;41:296-300.

2 Fernandez-Fernandez J, Zimek R, Wiewelhove $T$, et al. High-intensity interval training vs. repeated-sprint training in tennis. J Strength Cond Res 2012;26:53-62.

3 Mendez-Villanueva A, Fernandez-Fernandez J, Bishop D. Exercise-induced homeostatic perturbations provoked by single tennis match play with reference to development of fatigue. Br J Sports Med 2007:41:717-22

4 Kovacs M. Applied physiology of tennis performance. Br J Sports Med 2006:40:381-6.

5 Hornery DJ, Farrow D, Mujika I, et al. An integrated physiological and performance profile of professional tennis. Br J Sports Med 2007:41:531-6.

6 Gandevia SC. Spinal and supraspinal factors in human muscle fatigue. Physiol Rev 2001:81:1725-89.

7 Duffield R, Coutts AJ, Quinn J. Core temperature responses and match running performance during intermittent-sprint exercise competition in warm conditions J Strength Cond Res 2009:23:1238-44.

8 Coutts AJ, Quinn J, Hocking J, et al. Match running performance in elite Australian Rules Football. J Sci Med Sport 2010;13:543-8.

9 Girard 0, Racinais S, Micallef JP, et al. Spinal modulations accompany peripheral fatigue during prolonged tennis playing. Scan J Med Sci Sports 2011;21:455-64.

10 Ferrauti A, Pluim B, Weber K. The effect of recovery duration on running speed and stroke quality during intermittent training drills in elite tennis players. I Sports Sci 2001;19:235-42.

11 Fernandez J, Mendez-Villanueva A, Pluim BM. Intensity of tennis match play. Br J Sports Med 2006;40:387-91.

12 Groppel JL, Roetert EP. Applied physiology of tennis. J Sports Med 1992;14:260-8.

13 Bergeron MF, Maresh CM, Kraemer WJ, et al. Tennis: a physiological profile during match play. Int J Sports Med 1991;12:474-9.

14 Christmass MA, Richmond SE, Cable NT, et al. A metabolic characterisation of singles tennis. In: Reilly $T$, Hughes $M$, Lees $A$. eds. Science and racket sports. London: EF \& Spon, 1993:3-9.

15 Chandler TJ. Exercise training for tennis. Clin Sports Med 1995;14:33-47.

16 Elliott B, Dawson B, Pyke F. The energetics of singles tennis. J Hum Mov Stud 1985;11:11-20.

17 Ferrauti A, Bergeron MF, Pluim BM, et al. Physiological responses in tennis and running with similar oxygen uptake. Eur J Appl Physiol 2001;85:27-33.

18 Davey P, Thorpe R, Williams C. Fatigue decreases skilled tennis performance. J Sports Sci 2002:20:311-18.

19 Smekal G, Von Duvillard SP, Rihacek C, et al. A physiological profile of matchplay. Med Sci Sports Exerc 2001;33:999-1005.

20 Reilly T, Palmer J. Investigation of exercise intensity in males singles lawn tennis. In: Reilly T, Hughes M, Lees A. eds. Science and racket sports. London: EF \& Spon, 1993:10-13.

21 Morante SM, Brotherhood JR. Thermoregulatory responses during competitive singles tennis. Br J Sports Med 2007;41:779-83.

22 Ojala $T$, Häkkinen K. Effects of the tennis tournament on players' physical performance, hormonal responses, muscle damage and recovery. J Sports Sci Med 2013; 12:240-8

23 Filaire E, Alix D, Ferrand C, et al. Psychophysiological stress in tennis players during the first round single match of a tournament. Psychoneuroendocrinology 2009:34:150-7.

24 Booth A, Shelley G, Mazur A, et al. Testosterone, and winning and losing in human competition. Horm Behav 1989;23:556-71.

25 Hornery DJ, Farrow D, Mujika I, et al. Fatigue in tennis: mechanisms of fatigue and effect on performance. Sports Med 2007:37:199-212.

26 Kovacs M. A review of fluid and hydration in competitive tennis. Int J Sports Physiol Perform 2008;3:413-23.

27 Sawka MN, Montain SJ, Latzka WA. Hydration effects on thermoregulation and performance in the heat. Comp Biochem Physiol A Mol Integr Physiol 2001:128:679-90. 
28 Gomes RV, Moreira A, Coutts AJ, et al. Effect of carbohydrate supplementation on the physiological and perceptual responses to prolonged tennis match play. J Strength Cond Res 2013;In Press.

29 Chow JW, Carlton LG, Chae W, et al. Movement characteristics of the tennis volley. Med Sci Sports Exerc 1999:31:855-63.

30 Bernardi M, De Vito G, Falvo ME, et al. Cardiorespiratory adjustment in middle-level tennis players: are long term cardiovascular adjustments possible? Science and Racket Sports II. London: E\&FN Spon, 1998:20-6.

31 O'Donoghue P, Girard O, Reid M. Tennis. In: McGarry T, O'Donoghue P, Sampaio J. eds. Routeldge handbook of sports performance analysis. London: Routledge, 2013:404-14.

32 Fernandez Fernandez J, Sanz-Rivas D, Mendez-Villanueva A. A comparison of the activity profile and physiological demands between advanced and recreational veteran tennis players. J Str Cond Res 2009:23:604-10.

33 Ferrauti A, Weber K, Wright PR. Endurance: basic, semi-specific and tennis-specific. In: Reid M, Quinn A, Crespo M. eds. Strength and conditioning for tennis. Roehampton, London: International Tennis Federation, ITF Ltd, 2003:93-111.

34 Botton F, Hautier C, Eclache JP. Energy expenditure during tennis play: a preliminary video analysis and metabolic model approach. J Str Cond Res 2011;25: 3022-8

35 Robinson G, O'Donoghue PG. Movement in world class tennis on clay and grass courts: a case study. In: Hokelmann A, Brummond M. eds. Performance analysis of sport VIII. Aachen, Germany: Shaker-Verlag. 2008:720-4.

36 Geschiet D, Cormack S, Reid M, et al. Consecutive days of tennis match play affect physiological and performance responses [Thesis]. Melbourne, Australia: Australian Catholic University, 2013.

37 Duffield R, Reid M, Baker J, et al. Accuracy and reliability of GPS devices for measurement of movement patterns in confined spaces for court-based sports. I Sc Med Sport 2010;13:523-5.

38 Mohr M, Krustrup P, Bangsbo J. Match performance of high-standard soccer players with special reference to development of fatigue. J Sports Sci 2003;21:519-28.

39 Davey $\mathrm{P}$, Thorpe $\mathrm{R}$, Williams $\mathrm{C}$. Simulated tennis matchplay in a controlled environment. J Sports Sci 2003;21:459-67.

40 Vergauwen L, Brouns F, Hespel P. Carbohydrate supplementation improves stroke performance in tennis. Med Sci Sports Exerc 1998;30:1289-95.
41 Wu C, Shih M, Yang C, et al. Sodium bicarbonate supplementation prevents skilled tennis performance decline after a simulated match. J Int Soc Sports Nutr 2010;7:33.

42 Reid M, Duffield R, Dawson B, et al. Quantification of the physiological and performance characteristics of on-court tennis drills. Br J Sport Med 2008:42:146-51.

43 Lyons M, Al-Nakeeb Y, Hankey J, et al. The effect of moderate and high-intensity fatigue of groundstroke accuracy in expert and non-expert tennis players. J Sports Sci Med 2013;12:298-308.

44 Genevois C, Frican B, Creveaux T, et al. Effects of two training protocols on the forehand drive performance in tennis. J Strength Cond Res 2013:27:677-82.

45 Signorile JF, Sandler DJ, Smith WN, et al. Correlation analyses and regression modeling between isokinetic testing and on-court performance in competitive adolescent tennis players. J Strength Cond Res 2005;19:519-26.

46 Ellenbecker TS, Roetert EP. An isokinetic profile of trunk rotation strength in elite tennis players. Med Sci Sports Exerc 2004;36:1959-63.

47 Roetert EP, McCormack TJ, Brown SW, et al. Relationship between isokinetic and functional trunk strength in elite junior tennis players. Isokinet Exerc Sci 1996;6:15-20.

48 Kraemer WJ, Triplett NT, Fry AC. An in-depth sports medicine profile of women college tennis players. J Sport Rehabil 1995;4:79-98.

49 Pugh SF, Kovaleski JE, Heitman RJ, et al. Upper and lower body strength in relation to ball speed during a serve by male collegiate tennis players. Percept Mot Skill 2003;97:867-72

50 Girard O, Lattier G, Maffiuletti N, et al. Neuromuscular fatigue during a prolonged intermittent exercise: application to tennis. J Electromyogr Kinesio/ 2008;18:1038-46.

51 Girard O, Lattier G, Micallef JP, et al. Changes in exercise characteristics, maximal voluntary contraction, and explosive strength during prolonged tennis playing. $\mathrm{Br} \mathrm{J}$ Sports Med 2006;40:521-6.

52 Reid M, Duffield R, Minett GM, et al. Physiological, perceptual, and technical responses to on-court tennis training on hard and clay courts. J Strength Cond Res 2013:27:1487-95.

53 Murphy AP, Duffield R, Kellett A, et al. Comparison of athlete-coach perceptions of internal and external load markers for elite junior tennis training. Int J Sports Physiol Perform 2013; in press. 